Research Paper

\title{
Gender Related Survival Differences in ST-Elevation Myocardial Infarction Patients Treated with Primary PCI
}

\author{
Vojko Kanic $^{\circledR}$, Maja Vollrath², Franjo Husam Naji ${ }^{1}$, Andreja Sinkovic ${ }^{1}$ \\ 1. University Medical Centre Maribor, Maribor, Slovenia; \\ 2. Herzzentrum Leipzig, Leipzig, Germany. \\ $\triangle$ Corresponding author: Vojko Kanic, University Medical Centre Maribor, Division for Internal Medicine, Department of Cardiology and Angiology, \\ Ljubljanska ulica 5, 2000 Maribor, Slovenia, tel:+38623212901, fax:+3862331293 E-mail: vojko.kanic@guest.arnes.si. \\ ( ) Ivyspring International Publisher. Reproduction is permitted for personal, noncommercial use, provided that the article is in whole, unmodified, and properly cited. See \\ http://ivyspring.com/terms for terms and conditions.
}

Received: 2016.02.06; Accepted: 2016.05.08; Published: 2016.05.26

\begin{abstract}
Background: Data about gender as an independent risk factor for death in ST-elevation myocardial infarction (STEMI) patients is still contrasting. Aim was to assess how gender influences in-hospital and long-term all-cause mortality in STEMI patients with primary percutaneous coronary intervention $(\mathrm{PCl})$ in our region.

Methods: We analysed data from 2069 STEMI patients undergoing primary $\mathrm{PCl}$ in our institution from January 2009-December 2014, of whom 28.9\% were women. In-hospital and long-term mortality were observed in women and men. The effect of gender on in-hospital mortality was assessed by binary logistic regression modelling and by Cox regression analysis for long-term mortality.

Results: Women were older ( $68.3 \pm 61.8$ vs $61.8 \pm 12.0$ years; $p<0.0001)$, with a higher prevalence of diabetes $(13.7 \%$ vs $9.9 \% ; p=0.013)$ and tend to be more frequently admitted in cardiogenic shock (8.4\% vs $6.3 \% ; p=0.085)$. They were less frequently treated with bivalirudin $(15.9 \%$ vs $20.3 \%$; $\mathrm{p}=0.022$ ).

In-hospital mortality was higher among women $(14.2 \%$ vs $7.8 \% ; p<0.0001)$. After adjustment, age (adjusted OR: 1.05; 95\% Cl: 1.03 to 1.08; $\mathrm{p}<0.001$ ) and cardiogenic shock at admission (adjusted OR: 24.56; $95 \% \mathrm{Cl}$ : 11.98 to 50.35; p < 0.001), but not sex (adjusted OR: 1.47; $95 \% \mathrm{Cl}: 0.80$ to 2.71) were identified as prognostic factors of in-hospital mortality.

During the median follow-up of 27 months $(25$ th, 75 th percentile: 9,48$)$ the mortality rate $(23.6 \%$ vs $15.1 \%$; $<0.0001$ ) was significantly higher in women.

The multivariate adjusted Cox regression model identified age $(\mathrm{HR} 1.05 ; 95 \% \mathrm{Cl} 1.04-1.07$; $p<0.0001$ ), cardiogenic shock at admission (HR 6.09; 95\% Cl 3.78-9.81; $p<0.0001$ ), hypertension (HR 1.49; 95\% Cl 1.02-2.18; $\mathrm{p}<0.046)$, but not sex (HR 1.04; 95\% Cl 0.74-1.47) as independent prognostic factors of follow-up mortality.

Conclusion: Older age and worse clinical presentation rather than gender may explain the higher mortality rate in women with STEMI undergoing primary $\mathrm{PCl}$.
\end{abstract}

Key words: ST-elevation myocardial infarction, percutaneous coronary intervention, mortality, gender.

\section{Introduction}

Higher mortality rates were observed among women admitted with ST-elevation myocardial infarction (STEMI) in comparison to men (1-12). Data about gender as an independent prognostic factor for death is conflicting $(1-3,5,10,12-15)$. Underuse of evidence based treatment and delayed reperfusion are noticed in women (16-18). Women often delay seeking medical care compared with men probably because they experience more often atypical symptoms (16-18). Only a limited number of studies reported results about medium or long term mortality in women with STEMI receiving modern treatment 
$(1,15,19-21)$. Changes in percutaneous coronary intervention (PCI) practice and quality initiatives aimed at reducing door-to balloon times may have influenced these sex-related differences over time $(1,16)$. The aim of our study was to assess sex differences in in-hospital and follow-up outcomes in a retrospective cohort of STEMI patients undergoing primary PCI.

\section{Materials and methods}

The present study is a retrospective single-centre analysis of consecutive 2069 STEMI patients treated in our hospital from January 2009 to December 2014. Patients were treated according to the current guidelines for STEMI management (22). Angioplasty strategy, PCI of other coronary arteries and concomitant medication were at the discretion of the operator. Median follow-up time was 27 months (25th, 75th percentile: 9,48 ). The study was approved by the local ethical committee.

\section{Definitions}

To assess baseline clinical characteristics of the study cohort, we collected data concerning gender, diabetes, hypertension, dyslipidemia, all performed interventions, stents, lesions, interventions, TIMI grade flow before and after procedure and outcome. Data on dates of death were provided by Slovenian National Cause of Death Registry.

AMI definition was based on the current Guidelines (22,23). Thrombolysis in Myocardial Infarction (TIMI) flow grades were used for coronary flow assessment (24). Unsuccessful PCI was defined as PCI with TIMI grade flow $0 / 1$ after PCI.

Pain-to-first medical contact (FMC) time was defined as the time from symptom onset to FMC. FMC-to-cathlab time was the time from FMC to arrival in catheterization laboratory; FMC-to-balloon time was the time from FMC to balloon inflation (not wire passage). Cathlab-to-balloon time was the time from arrival in the cathlab to balloon inflation. Pain-to-balloon time was the time from symptom onset to balloon inflation.

\section{Outcomes}

The end points were all-cause in-hospital and follow-up mortality in male and female patients.

\section{Statistical methods}

Univariate logistic regression modelling was used to calculate adjusted odds of in-hospital mortality. Kaplan-Meier mortality curves for men and women were constructed. Cox proportional hazards regression was used to compute hazard ratios (HRs) as estimates for follow-up mortality.
Distributions of continuous variables in the two groups were compared with either the 2-sample t-test or the Mann-Whitney test according to whether data followed the normal distribution. Distributions of categorical variables were compared to the chi-square test. Data was analysed with the SPSS 21.0 software for Windows (SPSS, Inc., Chicago, Illinois). All p-values were two-sided; values less than 0.05 were considered statistically significant.

\section{Results}

\section{Descriptive data for patients}

Out of 2069 STEMI patients 597 (28.9\%) were female. Women were in average almost 7 years older $(61.8 \pm 12.0$ vs $68.3 \pm 12.6 ; p<0.0001)$ and almost $40 \%$ of them were older than 75 years $(p<0.0001)$. Significantly more women had diabetes $(9.9 \%$ vs 13.7 ; $\mathrm{p}=0.013$ ) and were less frequently treated with bivalrudin $(20.3 \%$ vs $15.9 ; \mathrm{p}=0.022)$. They tend to present themselves more often in cardiogenic shock $(6.3 \%$ vs $8.4 \% ; \quad p=0.085)$ Basic clinical and angiographic characteristics are shown in Table 1.

Table 1. Basic patients' clinical and angiographic characteristics.

\begin{tabular}{|c|c|c|c|c|}
\hline & $\begin{array}{l}\text { MEN } \\
N=1472 \\
(71.1 \%)\end{array}$ & $\begin{array}{l}\text { WOMEN } \\
\mathrm{N}=597 \\
(28.9 \%)\end{array}$ & $\begin{array}{l}\text { All patients } \\
\mathrm{N}=2069 \\
(100 \%)\end{array}$ & $\mathrm{p}$ \\
\hline Age, years $\infty$ & $61.8 \pm 12.0$ & $68.3 \pm 12.6$ & $63.7 \pm 12.5$ & $<0.0001$ \\
\hline Age $>75, \mathrm{~N}(\%)^{*}$ & 246 (16.7) & $231(38.7)$ & $477(23.1)$ & $<0.0001$ \\
\hline $\begin{array}{l}\text { Cardiogenic shock at } \\
\text { admission, } \mathrm{N}(\%)^{*}\end{array}$ & $92(6.3)$ & $50(8.4)$ & $142(6.9)$ & 0.085 \\
\hline Diabetes, N $(\%)^{*}$ & $146(9.9)$ & $82(13.7)$ & $228(11.0)$ & 0.013 \\
\hline Hypertension, $\mathrm{N}(\%)^{*}$ & $547(37.2)$ & $234(39.2)$ & $781(37.7)$ & 0.395 \\
\hline Dyslipidemia, N (\%)* & $472(32.1)$ & $179(30.0)$ & $651(31.5)$ & 0.375 \\
\hline Bivalirudin, $\mathrm{N}(\%)^{*}$ & $289(20.3)$ & $95(15.9)$ & $384(19.0)$ & 0.022 \\
\hline GPIIb/IIIa, N, $(\%)^{*}$ & $803(54.6)$ & $325(54.4)$ & $1128(54.5)$ & 1.000 \\
\hline PCI LMCA, N (\%)* & $45(3.1)$ & $23(3.9)$ & $86(3.3)$ & 0.344 \\
\hline PCI LAD, N (\%) & $652(44.3)$ & $270(45.2)$ & $922(44.6)$ & 0.733 \\
\hline PCI LCX, N $(\%)^{*}$ & $274(18.8)$ & $90(15.1)$ & $364(17.6)$ & 0.056 \\
\hline PCI RCA, N $(\%)^{*}$ & $518(35.2)$ & $230(38.5)$ & $748(36.2)$ & 0.158 \\
\hline Unsuccessful PCI, N (\%)* & $54(3.7)$ & $31(5.2)$ & $85(4.1)$ & 0.114 \\
\hline Multivessel PCI, N $(\%)^{*}$ & $181(12.3)$ & $66(11.1)$ & 247 (11.9) & 0.455 \\
\hline Radial, N (\%)* & $156(10.6)$ & $54(9.0)$ & $210(10.0)$ & 0.335 \\
\hline $\mathrm{IABP}, \mathrm{N}(\%)^{*}$ & $35(2.4)$ & $22(3.7)$ & $57(2.8)$ & 0.104 \\
\hline DES, N $(\%)^{*}$ & $526(35.7)$ & $216(36.2)$ & $742(35.9)$ & 0.879 \\
\hline $\begin{array}{l}\text { TIMI } 3 \text { at admission, } \mathrm{N} \\
(\%)^{*}\end{array}$ & $63(4.3)$ & $30(5.0)$ & $93(5.0)$ & 0.483 \\
\hline TIMI3 after PCI, N (\%)* & $1172(79.6)$ & $485(81.2)$ & $2069(100)$ & 0.430 \\
\hline
\end{tabular}

$\infty$ Mean (standard deviation); comparison made using the t-test.; ${ }^{*}$ Comparison made using the chi-square test;

$\mathrm{DES}=$ drug eluting stent; $\mathrm{GPI}=\mathrm{GPII}$-IIIa receptor inhibitors; IABP $=$ intra-aortic balloon pump insertion; $\mathrm{LAD}=$ left anterior descendent artery; $\mathrm{LCX}=$ circumflex artery; LMCA = left main coronary artery; Multivessel PCI $=$ PCI of more than one major coronary artery, $\mathrm{PCI}=$ percutaneous coronary intervention; Radial = radial approach; RCA = right coronary artery; TIMI3 after PCI = TIMI 3 grade flow after procedure; TIMI 3 at admission = TIMI grade flow before procedure; Unsuccessful $\mathrm{PCI}=$ TIMI grade flow after PCI $=0 / 1$ 


\section{Time to treatment}

Median pain-to-FMC time (110min in men vs $133 \mathrm{~min}$ in women) and cathlab-to-balloon time (24min vs $25 \mathrm{~min}$ ) were similar in both groups (Table 2).

The time from FMC-to-cathlab (73min vs $82 \mathrm{~min}$; $\mathrm{p}=0.009$ ), the time from FMC-to-balloon $(100 \mathrm{~min}$ vs 107min; $p=0.004$ ) and the pain-to-balloon time (225min vs $244 \mathrm{~min} ; \mathrm{p}=0.042$ ] were longer in women (Table 2).

\section{Mortality}

\section{In-hospital mortality}

Women had a significantly higher in-hospital mortality [115 men (7.8\%) died vs 85 women (14.2\%); $\mathrm{p}<0.0001]$ (Table 3). Unadjusted women-to-men odds ratio for mortality was 1.96 (95\% confidence interval 1.45 to $2.64 ; p<0.0001)$. The difference was no longer significant after multivariate analysis (adjusted OR: 1.47; $95 \%$ CI: 0.80 to 2.71 ). Age (adjusted OR: $1.05 ; 95 \%$ CI: 1.03 to $1.08 ; \mathrm{p}<0.001$ ) and cardiogenic shock (adjusted OR: 24.56; 95\% CI: 11.98 to 50.35; $\mathrm{p}<0.001$ ) at presentation were identified as independent prognostic factors of increased in-hospital overall mortality.

\section{Follow-up mortality}

Women had a significantly higher follow-up mortality during the observation period; $\log$ Rank $<0.0001$ (Table 3, Figure 1).

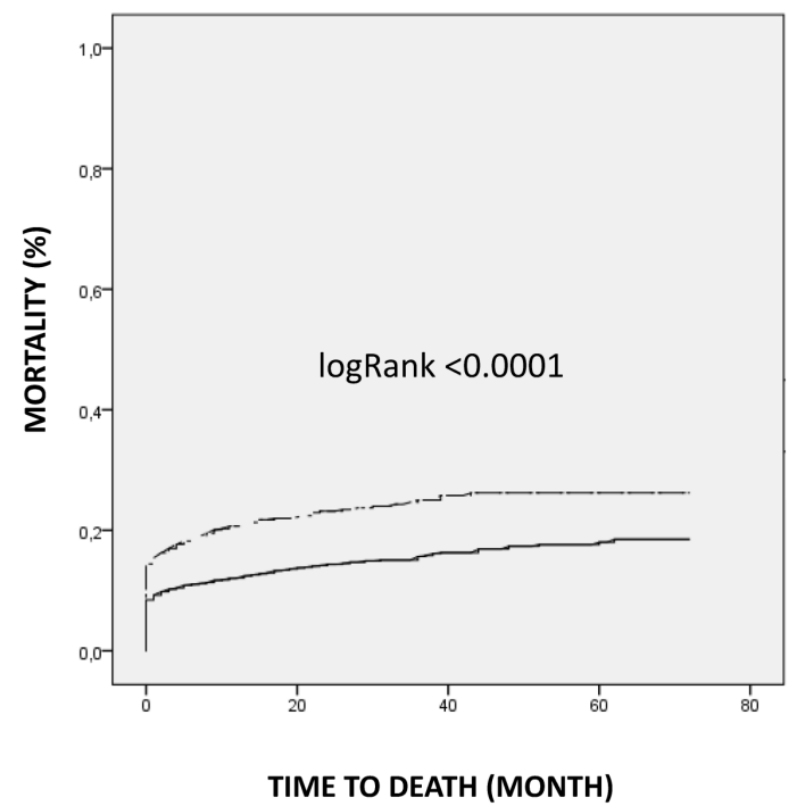

Figure 1. Follow-up mortality in STEMI patients among men and women. Women = dashed line; Men $=$ solid line .
The multivariate Cox regression analysis identified age (HR 1.05; 95\% CI 1.04-1.07; p<0.0001), cardiogenic shock (HR 6.09; 95\% CI 3.78-9.81; $\mathrm{p}<0.0001$ ), hypertension (HR 1.49; 95\% CI 1.02-2.18; $\mathrm{p}<0.046$ ) but not gender (HR 1.04; 95\% CI 0.74-1.47) as independent prognostic factors of increased long-term mortality.

\section{Quality of care}

Women were brought to hospital with a delay [FMC-catheterization laboratory time was longer for women (73min vs 82min; p=0.009)] and less often received bivalirudin. Otherwise they were treated as aggressive as men but with the median time delay of 19 minutes (Table 1,2).

Table 2. Time to treatment among men and women.

\begin{tabular}{|c|c|c|c|c|}
\hline & $\begin{array}{l}\text { MEN }(N= \\
1472)\end{array}$ & $\begin{array}{l}\text { WOMEN }(\mathrm{N} \\
=597)\end{array}$ & $\begin{array}{l}\text { ALL } \\
\text { PATIENTS }(\mathrm{N} \\
=2069)\end{array}$ & $\mathrm{p}$ \\
\hline Pain-to-FMC, $(\min )^{*}$ & $110(50,250)$ & $133(53,261)$ & $117(50,251)$ & 0.140 \\
\hline $\begin{array}{l}\text { FMC-to-cathlab } \\
(\min )^{¥}\end{array}$ & $73(50,107)$ & $82(57,123)$ & $75(52,112)$ & 0.009 \\
\hline $\begin{array}{l}\text { FMC-to-balloon, } \\
(\mathrm{min}) ¥\end{array}$ & $100(75,135)$ & $107(82,158)$ & $103(77,142)$ & 0.004 \\
\hline $\begin{array}{l}\text { Cathlab-to-balloon, } \\
(\min )^{¥}\end{array}$ & $24(18,30)$ & $25(17,34)$ & $24(18,31)$ & 0.146 \\
\hline $\begin{array}{l}\text { Pain-to-balloon, } \\
(\mathrm{min})^{¥}\end{array}$ & $225(148,387)$ & $244(160,446)$ & $230(150,397)$ & 0.042 \\
\hline
\end{tabular}

Table 3. Mortality in men in women after STEMI.

\begin{tabular}{|c|c|c|c|c|}
\hline MORTALITY & $\begin{array}{l}\text { MEN }(\mathrm{N} \\
=1472)\end{array}$ & $\begin{array}{l}\text { WOMEN }(\mathrm{N} \\
=597)\end{array}$ & $\begin{array}{l}\text { ALL PATIENTS } \\
(\mathrm{N}=2069)\end{array}$ & $\mathrm{P}$ \\
\hline In-hospital, $\mathrm{N}(\%)^{*}$ & $115(7,8)$ & $85(14,2)$ & $200(9.7)$ & $<0.0001$ \\
\hline $\begin{array}{l}\text { Follow-up mortality, } \\
\mathrm{N}(\%)^{*}\end{array}$ & $222(15,1)$ & $141(23,6)$ & 363 (17.5) & $<0.0001$ \\
\hline
\end{tabular}

\section{Discussion}

The key findings of our analysis were:

- women were older, with higher prevalence of diabetes and a higher occurrence of severe hemodynamic impairment;

- higher in-hospital and follow-up mortality were observed among women, however the difference disappeared after age adjustment and gender was not independently associated with in-hospital and long-term mortality;

- the quality of care was similar as far as it concerns door-to-balloon time and procedural success, but women were treated with a time delay and received less bivalirudin.

Women were almost 7 years older than men, had 
more comorbidities and tend to have more hemodynamic impairment which is in accordance to previous observations $(1-4,6,7,9,10,13,14,25-28)$.

Higher unadjusted women's in-hospital mortality in STEMI patients undergoing primary PCI was also previously described $(1,3,8,9,11,15)$. However data about gender as an independent prognostic factor for death is still conflicting $(1,10,12-14)$. In-hospital mortality was not independently linked to female gender after adjustment for age, comorbidities and clinical picture at admission in most studies $(1-4,6,15,20,29)$, but some had noticed that female sex was linked with a higher mortality (9-12).

The same is true for long-term mortality. The majority of studies show a gender difference in long-term mortality rates $(10,15,30)$, but some showed no gender difference $(6,9,20,27)$. Differences in the mortality rate after adjustments persisted only in one study and only in patients younger than 65 years (30).

In our study gender was not an independent predictor neither for in-hospital nor for long-term mortality after adjustments for confounders.

Data about longer ischemic time in women is still contrasting $(12,13,29)$. Women in our study had a longer total ischemic time compared to men as it was seen before $(6,10,12,13,15,31)$. Any delay in restoring reperfusion results in a larger infarct and thus may contribute to the poorer outcomes (13-32). The delay in presentation to hospital may be due to atypical symptoms and the underestimation of the prevalence of coronary heart disease amongst women within the community (13). Welders et al. found that every 10 minutes longer ischemic time results in additional $1 \%$ higher 7-day-mortality. The median difference in ischemic time in our study was 19 minutes. However in contrast to the mentioned study the observed difference in ischemic time was not the predictor for in-hospital or follow-up mortality after adjustments.

The results of our study may influence the daily clinical practice. Particular attention should be paid to women. They experience more often atypical symptoms (nausea, shortness of breath, back, neck and yaw pain, indigestion, palpitations, dizziness, fatigue, loss of appetite, and syncope) $(13,17)$. Even after STEMI is recognized, the "sense of urgency" may be lost by the triage personnel resulting in a less urgent triage classification and subsequent delay (13). This may explain longer FMC-catheterization laboratory time in our study.

\section{Limitations}

There are limitations of this study that merit being mentioned. Firstly this was an observational and a single-centre study. Secondly our data encompassed all-cause mortality only which is certainly considered to be a limitation of the study. Finally, data about bleeding and smoking were not collected.

\section{Conclusion}

Our study showed that gender was not a predictor for a higher mortality in STEMI patients. In order to achieve a better survival-rate of women with STEMI, they should be treated as aggressive and fast as men. Furthermore women should be informed about the atypical presentation of STEMI and the importance of an immediate medical contact after the start of symptoms.

\section{Competing Interests}

The authors have declared that no competing interest exists.

\section{References}

1. Jackson EA, Moscucci M,Smith DE, et al. The association of sex with outcomes among patients undergoing primary percutaneous coronary intervention for ST elevation myocardial infarction in the contemporary era: Insights from the Blue Cross Blue Shield of Michigan Cardiovascular Consortium (BMC2). Am Heart J. 2011;161:106-12.

2. Calé $\mathrm{R}$, de Sousa $\mathrm{L}$, Pereira $\mathrm{H}$, et al. Primary angioplasty in women: Data from the Portuguese Registry of Interventional Cardiology. Rev Port Cardiol. 2014;33:353-61.

3. Biava LM, Scacciatella P, Calcagnile C, et al. Sex-related differences in patients with ST-elevation myocardial infarction undergoing primary PCI: A long-term mortality study. Cardiovasc Revasc Med. 2015;16:135-40.

4. Bavishi C, Bangalore S, Patel D, et al. Short and long-term mortality in women and men undergoing primary angioplasty: A comprehensive meta-analysis. International Journal of Cardiology. 2015;198:123-30.

5. Gevaert SA, De Bacquer D, Evrard P, et al. Gender, TIMI risk score and in-hospital mortality in STEMI patients undergoing primary PCI: results from the Belgian STEMI registry. EuroIntervention. 2014;9:1095-101.

6. Hurtado-Martínez J, Pinar-Bermúdez E, Teruel-Carrillo F, et al. In-hospital and long-term mortality in women with acute myocardial infarction treated by primary angioplasty. Rev Esp Cardiol. 2006;59:1113-22.

7. Abdel-Qadir HM, Ivanov J, Austin PC, et al. Sex differences in the management and outcomes of Ontario patients with cardiogenic shock complicating acute myocardial infarction. Can J Cardiol. 2013:29:691-6.

8. Kuhn L, Page K, Rahman MA, et al. Gender difference in treatment and mortality of patients with ST-segment elevation myocardial infarction admitted to Victorian public hospitals: A retrospective database study. Aust Crit Care. 2015;28:196-202.

9. Lawesson SS, Alfredsson J, Fredrikson M, et al. A gender perspective on shortand long term mortality in ST-elevation myocardial infarction--a report from the SWEDEHEART register. Int J Cardiol. 2013;168:1041-7.

10. Sadowski M, Gasior M, Gierlotka M, et al. Gender-related differences in mortality after ST-segment elevation myocardial infarction: a large multicentre national registry. EuroIntervention. 2011;6:1068-72.

11. Valente S, Lazzeri C, Chiostri $M$, et al. Gender-related difference in ST-elevation myocardial infarction treated with primary angioplasty: a single-centre 6-year registry. Eur J Prev Cardiol. 2012;19:233-40.

12. I Velders MA, Boden $\mathrm{H}$, van Boven $\mathrm{AJ}$, et al. Influence of gender on ischemic times and outcomes after ST-elevation myocardial infarction. Am J Cardiol. 2013;111:312-8.

13. Dreyer RP, Beltrame JF, Tavella R, et al. Evaluation of gender differences in Door-to-Balloon time in ST-elevation myocardial infarction. Heart Lung Circ. 2013;22: 861-9

14. Koeth $\mathrm{O}, \mathrm{Zahn} \mathrm{R}$, Heer $\mathrm{T}$, et al. Gender differences in patients with acute ST-elevation myocardial infarction complicated by cardiogenic shock. Clin Res Cardiol. 2009;98:781-6.

15. van der Meer MG, Nathoe HM, van der Graaf Y, et al. Worse outcome in women with STEMI: a systematic review of prognostic studies. Eur J Clin Invest. 2015;45:226-35.

16. Jneid H,Fonarow GC, Cannon CP, et al. Sex differences in medical care and early death after acute myocardial infarction. Circulation. 2008;118:2803-10.

17. Crea F, Battipaglia I, Andreotti F. Sex differences in mechanisms, presentation and management of ischaemic heart disease. Atherosclerosis. 2015;241:157-68.

18. Andreotti F, Marchese N. Women and coronary disease. Heart. 2008;94:108-16. 
19. Ergelen M, Uyarel H, Gorgulu S, et al. Comparison of outcomes in young versus nonyoung patients with ST elevation myocardial infarction treated by primary angioplasty. Coron Artery Dis. 2010;21:72-7.

20. Sjauw KD, Stegenga NK, Engström AE, et al. The influence of gender on shortand long-term outcome after primary PCI and delivered medical care for ST-segment elevation myocardial infarction. EuroIntervention. 2010; 5:780-7.

21. Wijnbergen I, Tijssen J, van 't Veer M, et al. Gender differences in long-term outcome after primary percutaneous intervention for ST-segment elevation myocardial infarction. Catheter Cardiovasc Interv. 2013;82:379-84.

22. Steg G James SK, Atar D, et al. ESC Guidelines for the management of acute myocardial infarction in patients presenting with ST-segment elevation. Eur Heart J 2012;33:2569-619.

23. Thygesen K, Alpert JS, Jaffe AS, et al. Third universal definition of myocardial infarction. Eur Heart J. 2012;33:2551-67.

24. White CW Simplicity's virtue scorned. Precision comes to TIMI flow grading and the results are ...surprising. Circulation. 1996;93: 853-6.

25. Brieger D, Eagle KA, Goodman SG, et al. Acute Coronary Syndromes Without Chest Pain, An Underdiagnosed and Undertreated High-Risk Group. CHEST. 2004;126:461-9.

26. Khera S, Kolte D1, Gupta T, et al. Temporal Trends and Sex Differences in Revascularization and Outcomes of ST-Segment Elevation Myocardial Infarction in Younger Adults in the United States. J Am Coll Cardiol. 2015;66:1961-72.

27. Bufe A, Wolfertz J, Dinh W, et al. Gender-based differences in long-term outcome after ST-elevation myocardial infarction in patients treated with percutaneous coronary intervention. J Womens Health (Larchmt). 2010;19:471-5.

28. Ghauharali-Imami S, Bax M, Haasdijk A, et al. The impact of gender on long-term mortality in patients with multivessel disease after primary percutaneous coronary intervention. Neth Heart J. 2015;23:592-9.

29. Brown RA, Shantsila E, Varma C1, et al. Symptom-to-door times in patients presenting with ST elevation myocardial infarction-do ethnic or gender differences exist? QJM. 2015; pii: hcv112.

30. Otten AM, Maas AH, Ottervanger JP, et al. Is the difference in outcome between men and women treated by primary percutaneous coronary intervention age dependent? Gender difference in STEMI stratified on age. Eur Heart J Acute Cardiovasc Care. 2013;2:334-41.

31. Goldberg RJ, Steg PG, Sadiq I, et al. Extent of, and factors associated with, delay to hospital presentation in patients with acute coronary disease (the GRACE registry). Am J Cardiol. 2002;89:791-6.

32. De Luca G, Suryapranata H, Ottervanger JP, et al. Time delay to treatment and mortality in primary angioplasty for acute myocardial infarction: every minute of delay counts. Circulation. 2004; 109:1223-5. 